\title{
The Interrelation between Cognitive Styles and Copying Strategies among Student Youth
}

\author{
Alfiya R. Masalimova ${ }^{1 *}$, Mikhail N. Mikhaylovsky ${ }^{2}$, Aleksandr V. Grinenko ${ }^{3}$, Marina E. Smirnova ${ }^{4}$, \\ Lilia B. Andryushchenko ${ }^{5}$, Mariya A. Kochkina ${ }^{6}$, Igor G. Kochetkov ${ }^{7}$ \\ ${ }^{1}$ Kazan (Volga region) Federal University, Kazan, RUSSIA \\ ${ }^{2}$ The Sechenov First Moscow State Medical University, Moscow, RUSSIA \\ ${ }^{3}$ Moscow State Institute of International Relations (University) of the Ministry of Foreign Affairs, Moscow, RUSSIA \\ ${ }^{4}$ Financial University under the Government of the Russian Federation, Moscow, RUSSIA \\ ${ }^{5}$ Plekhanov Russian University of Economics, Moscow, RUSSIA \\ ${ }^{6}$ The Russian Presidential Academy of National Economy and Public Administration (Lipetsk Branch), Lipetsk, RUSSIA \\ ${ }^{7}$ Ulyanovsk State University, Ulyanovsk, RUSSIA
}

Received 18 July 2018 • Revised 14 November 2018 • Accepted 21 December 2018

\begin{abstract}
The article deals with the problem of studying the issues of creative thinking, cognitive styles and coping strategies among students. The importance of this problem is determined by contemporary society and its social demand, requiring that a young specialist should be creative, he should have a non-standard approach, he could generate new ideas that can help him cope with difficulties and resolve stressful situations. An empirical study was conducted to analyze the relationship between the indicators of creative thinking, the cognitive styles of "Field Dependence-Field independence" and students' coping strategies. Fifty-two people participated in it, among them 26 students of the Faculty of Humanities of Ulyanovsk State University and 26 students of the Institute of Mathematics and Mechanics of Kazan Federal University. The interpretation of this study results allowed us to draw the major conclusions: students of humanities programs with developed creative thinking are focused on external factors, do not strive to avoid problem resolution, but when they encounter a problem situation, the primary negative reaction prevents them from resolving it quickly, thereby enabling them to correctly plan and find optimal ways out of this stressful situation; creative students-mathematicians are less susceptible to external factors, have a high control of emotions, they are capable of generating new solutions, which allows them to take conscious steps to solve the problem.
\end{abstract}

Keywords: creative thinking, cognitive styles, field addiction, field independence, coping strategies, ways of coping behavior, student youth, study of interrelation

\section{INTRODUCTION}

In today, the study of the problem of creative thinking is becoming ever more important, since contemporary society needs a creative specialist who is able to approach problem issues, in an unusual way, generate a huge number of new ideas, move away from patterns and ways of standard thinking, which confirms the important role of cognitive processes with which a person perceives, organizes and processes external information. At the same time, special attention is paid to studying the problem of coping with stressful situations, as the modern pace of life is so intense, eventful and accompanied by the emergence of constant problems. This is especially important and significant for students who are in the stage of uncertainty, emotional experiences and personal self-determination. Thus, we can conclude that at present the interrelation between creative thinking, cognitive styles and coping

(C) 2019 by the authors; licensee Modestum Ltd., UK. This article is an open access article distributed under the terms and conditions of the Creative Commons Attribution License (http://creativecommons.org/licenses/by/4.0/). \alfkazan@mail.ru (*Correspondence) $\square$ minih200707@yandex.ru $\$ avgrinenko2@mail.ru 


\section{Contribution of this paper to the literature}

- The authors have provided insight into the problem of the interrelation between creative thinking, cognitive styles and coping strategies among students.

- It has been proved in the article that there is an interrelationship between creative thinking indicators, cognitive styles "Field dependence-Field independence" and strategies of coping behavior among students.

- The results of the study indicate that humanities students with developed creative thinking are focused on external factors, do not seek to avoid resolving problems, but when they encounter a problem situation, the primary negative reaction prevents them from resolving it quickly, thereby giving them an opportunity to plan skillfully and find the best way out of this stressful situation.

- The authors have proved that the students-mathematicians are less susceptible to the influence of external factors. They have high control of the emotional sphere; they are able to come up with new solutions. It allows them to take conscious steps to solve a problem.

strategies among students have a great response in society, they are not well understood and, therefore, require a more detailed study.

Scientists began studying the problems of creative thinking from the beginning of the 20 $0^{\text {th }}$ century. The majority of studies on this topic is connected with the names of foreign and domestic psychologists, such as Guilford (2015), Torrens (2006), Bogoyavlenskaya $(2002,2011)$. The authors treated creative thinking as a function of the psyche, the ability to tackle tasks quickly, to be non-standard, independent, self-confident. Creative thinking is something that is intrinsic to every person without exception, but it is worth noting that it depends on individual and personal qualities, motivation, and also cognitive properties of a person.

Cognitive styles have been actively studied since the 1950-s of the last century by foreign and domestic scientists, such as Kholodnaya (2004), Witkin (1981), Carrol (1993). They considered cognitive styles as a stable system of the ways of cognitive activity, which determines the ways of thinking, perception and processing of information, which manifest themselves in solving various problems in various problem situations. For example, people with different prevalence of a cognitive style, respectively, will have different ways of behavior and finding a way out of stressful situations.

Scientists began to deal with strategies of coping behavior (coping strategies) of the individual from the second half of the $20^{\text {th }}$ century. A great number of studies on this topic are connected with the names of foreign domestic psychologists, such as Lazarus and Folkman (1984), Antsyferova (1994), Kryukov (2008). They interpreted coping strategies or strategies of coping behavior as the ways to overcome difficulties. These are the actions to maintain harmony between the requirements of the environment and resources that satisfy these requirements. As a result, a person reduces the negative effects of a stressful situation or adapts to it, without trying to overcome it.

Despite a vast theoretical base of the study and keen interest in the phenomena of creative thinking, cognitive styles and coping strategies, psychological science has not considered yet the practical experience of studying the interrelation between these elements and the influence of each of them on one another. This emphasizes the importance of this issue and is indeed of particular interest to modern psychology (Belinskaya \& Pronina, 2017; Gnedova et al., 2015; Lipatova et al., 2015; Masalimova \& Chibakov, 2016; Masalimova et al., 2014; Masalimova \& Shaidullina, 2017).

\section{METHODOLOGICAL FRAMEWORK AND METHODS}

The sample group of our study was composed of Ulyanovsk State and Kazan Federal Universities" students, the total number of subjects - 52 people aged from 17 to 21: 26 students of the Faculty of Humanities and Social Technologies (Ulyanovsk State University), 26 students of the Institute of Mathematics and Mechanics (Kazan Federal University). Each respondent underwent the diagnostic assessment with the use of three techniques: J. Bruner's technique of determining the types of thinking and the level of creativity, K. Gottschald's test "Included figures" and the questionnaire "The ways of coping behavior" by Lazarus (Bruner, 1971, 1977; Lazarus \& Folkman, 1984).

\section{RESULTS AND DISCUSSION}

We conducted a correlation analysis of the research results to identify the interrelation between creative thinking and coping strategies among students of the Faculty of Humanities and Social Technologies and the students of the Institute of Mathematics and Mechanics. To this end, the data obtained was subjected to the mathematical analysis using the Spearman $r$-test (Figure 1). Critical values of the criterion $r_{s}=0.39$ at $p \leq 0.05$ and $\mathrm{r}_{\mathrm{s}}=0.50$ at $\mathrm{p} \leq 0.01$ 


\section{Faculty of Humanities Faculty of Mathematics}



Figure 1. The results of the correlation analysis between the indicators of creative thinking and coping strategies

1 - Confrontation;

2 - Keeping smb. at a distance;

3 - Self-control;

4 - Search for support;

5 - Accepting responsibility;

6 - Escape-Avoidance;

7 - Problem solving planning;

8 - Positive reassessment.

As a result, a significant positive correlation coefficient of creative thinking and coping strategy "Confrontation" $\left(r_{s}=0.396\right.$ at $\left.p \leq 0.05\right)$ was found among students of humanities programs. This indicates that creative people react or show some aggressiveness towards a situation that is difficult to solve. It is worth noting that confrontation is an emotionally focused strategy, that is, it touches upon the emotional response to a problem, and creative people are distinguished by the presence of spontaneous reactions and emotional mobility. Such a person finds hard to plan his own behavior, to predict the outcome of the situation, sometimes he acts thoughtlessly and unreasonably. Probably, after an emotional outburst and a vivid reaction to the situation, a creative person will be able to direct his energy to socially approved actions, uncover the potential and realize his natural abilities. Thus, the higher the level of creativity of a person, the sooner he will react aggressively when solving difficult life situations.

A significant positive correlation between creative thinking and coping strategies "Problem solving planning" $\left(r_{\mathrm{s}}=0.427\right.$ at $\left.\mathrm{p} \leq 0.05\right)$ was also found among students of the Institute of Mathematics and Mechanics. Such an indicator testifies to the fact that such creative individuals analyze a stressful situation, but act taking account of experience and resources that a person has. The coping strategy "Problem solving planning" is a problem-oriented strategy, it is connected with a rational analysis of a stressful situation and contributes to its constructive resolution. It should be noted that people with a high rate of creative thinking are independent of other people's opinions, rely on their own powers, they take the initiative, persistent. It helps them to take conscious steps to resolve a difficult life situation. To find new and non-standard solutions to problematic issues, to generate new ideas is also typical of creative people, so they have more opportunities to find the optimal way out of the current situation.

Further, our analysis was devoted to the interrelation between the levels of creative thinking and the cognitive styles of "Field dependence" and "Field independence". For this purpose, the data obtained was also subjected to the mathematical analysis using the Spearman r-test (Figure 2). According to the results, students of the Faculty of Humanities and Social Technologies have a negative or inversely proportional correlation coefficient on the scale "Field dependence" $\left(r_{s}=-0.099\right)$, which suggests that one of the indicators may increase, while the other - decrease and on the scale "Field independence", a positive correlation coefficient is expressed $\left(\mathrm{r}_{\mathrm{s}}=0.178\right)$. However, these indicators do not reach the level of statistical significance, which indicates an insignificant correlation. Students of the Institute of Mathematics and Mechanics on the scales "Field dependence" and "Field independence" have an inversely proportional correlation coefficient $\left(r_{s}=-0.316\right.$ and $r_{s}=-0.094$, respectively), these figures also do not reach the level of statistical significance. 


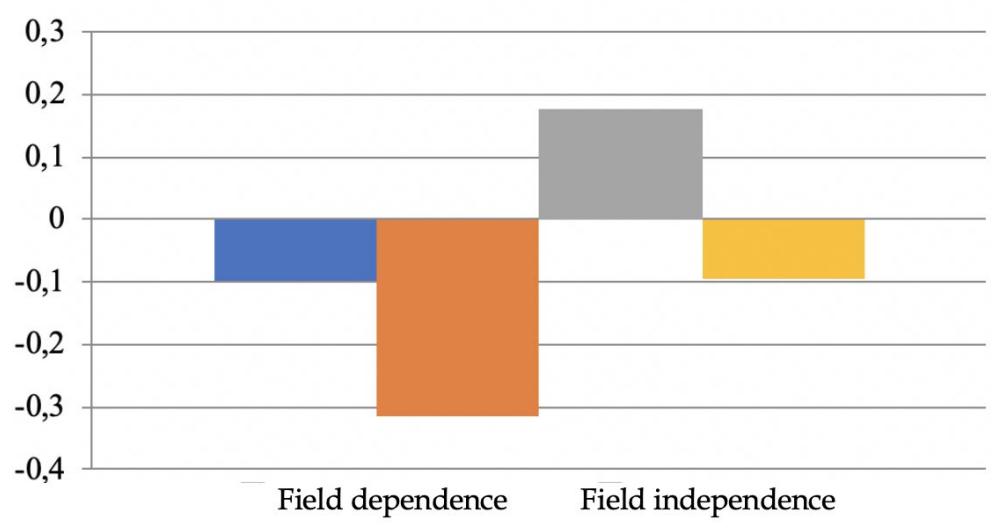

Figure 2. The results of the correlation analysis between the indicator of creative thinking and the cognitive styles "Field dependence" and "Field independence"

Faculty of Humanities Field dependence

Faculty of Mathematics Field dependence
Faculty of Humanities Field independence

Faculty of Mathematics Field independence

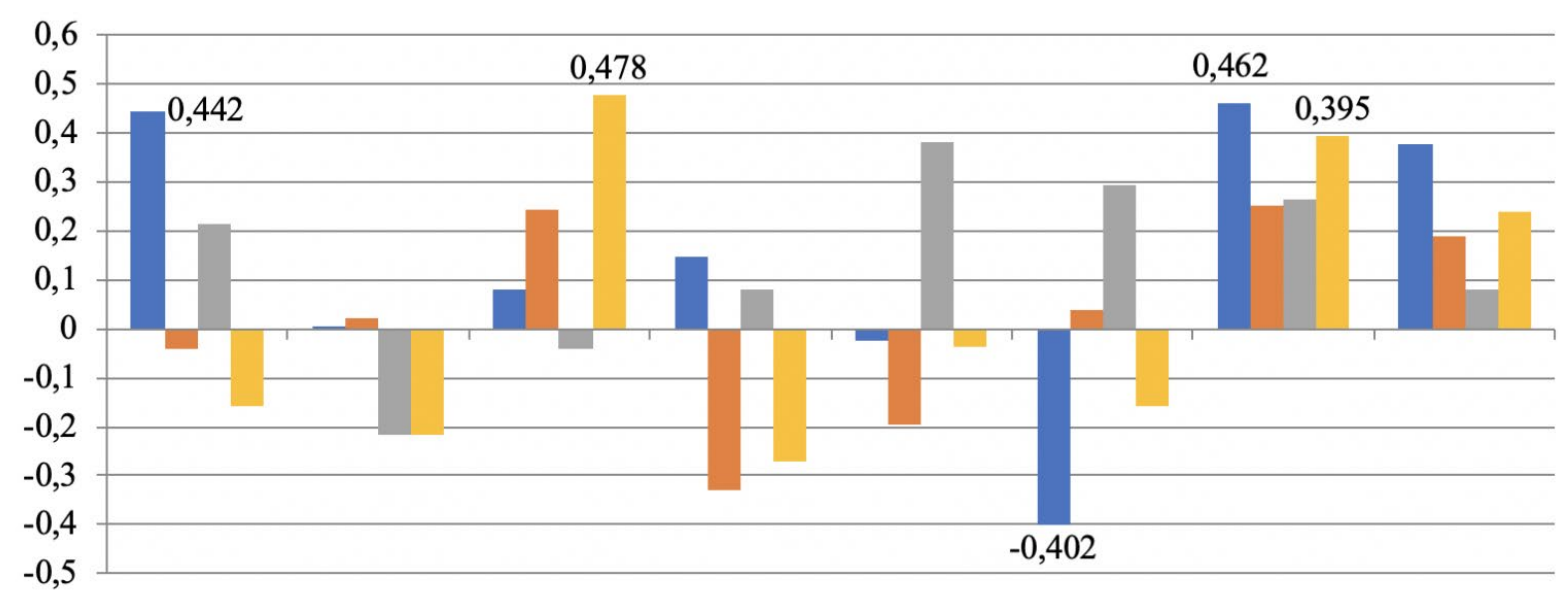

Figure 3. The results of the correlation analysis between the cognitive styles "Field dependence" and "Field independence" and coping strategies

Further analysis was devoted to the interrelation between the cognitive styles of "Field dependence-Field independence" and coping strategies. To this end, the data obtained was subjected to the mathematical analysis with the use of the Spearman r-test (Figure 3).

As a result, a significant positive correlation between the cognitive style "Field dependence" and the coping strategy "Confrontation" was found in students of the Faculty of Humanities $\left(\mathrm{r}_{\mathrm{s}}=0.442\right.$ at $\left.\mathrm{p} \leq 0.05\right)$. This indicates that such people are focused on external factors, possess social skills, easily interact with other people, they are more sensitive to other people. But in the process of communication, they can show excessive obstinacy, negative emotional reactions, express their opinions and actively defend them, creating a conflict and stressful situation for themselves. Consequently, in this case, confrontation will not be a solution to the problem, but only a certain psychological release, the relief from psycho-emotional stress.

A significant positive correlation of the cognitive style "Field dependence" was also found in the coping strategy indicator "Planning problem solving" ( $r_{s}=0.462$ at $\left.\mathrm{p} \leq 0.05\right)$. Psychologists consider this strategy as adaptive one. It contributes to the constructive resolution of difficulties. This can testify to good skills of social interaction, sociability, trust and empathy towards others, provides an opportunity to establish new contacts and acquaintances, which, based on existing social experience, can help to develop a specific plan for resolving the current situation. But such a person is probably dependent on the group, often hears the opinions of others. 
Therefore, relatives, friends, authoritative personalities, people whom he trusts can help him in finding the best solutions.

A negative correlation of the cognitive style "Field dependence" was found in the indicator of the coping strategy "Escape-Avoidance" $\left(r_{s}=-0.402\right.$ at $\left.p \leq 0.05\right)$. This indicates that these variables change inversely proportional: if one increases, then the other decreases and vice versa. Accordingly, students with a pronounced field dependence tend to self-control, have high control of behavior, are willing to take responsibility for their actions. Therefore, they do not avoid solving problems, know how to build social contacts, defend their own interests and cope with stress in a difficult situation. Those students who are cautious and indecisive when communicating with people, do not depend on the opinions of others have less pronounced field dependence. Probably they have psychological barriers, that is why, they evade solving the problem. A complete disregard, an incorrect assessment of what is happening is possible, evading responsibility, passivity and keeping the parties of the conflict at a distance.

We found a significant positive correlation between the cognitive style "Field independence" and the coping strategy "Self-control" in students of the Institute of Mathematics and Mechanics $\left(\mathrm{r}_{\mathrm{s}}=0.478\right.$ at $\left.\mathrm{p} \leq 0.05\right)$. Fieldindependent students tend to be independent, critical and demanding of themselves and others, purposefully keep a distance when communicating with others. Therefore they are less susceptible to external factors, and they are also good at hiding their feelings and emotions that they experience in connection with a difficult situation. Consequently, they are independent, disciplined, have high self-control, and the restraint shown by them helps them to save emotional energy and redirect it to the effective resolution of a problem situation.

Students-mathematicians were found to have a significant positive correlation of the cognitive style "Field independence" and the coping strategy "Planning problem solving" ( $\mathrm{r}_{\mathrm{s}}=0.395$ at $\left.\mathrm{p} \leq 0.05\right)$. Students with pronounced field independence have high intelligence, are able to control and restrain their emotions. They are focused on the search, they are able to generate new solutions and develop strategies to overcome difficult life situations. They prefer to independently analyze the problem and predict the consequences of their actions. Consequently, they have more opportunities to find the most acceptable way out of a problem situation, they are distinguished by a long duration of preparatory and control actions to solve the problem. They use emotional coping strategies less often, which contributes to the most constructive and productive resolution of the problem.

Analyzing the discovered interrelationships between creative thinking, cognitive styles and coping strategies of students of the Faculty of Humanitarian and the Institute of Mathematics and Mechanics, one can say that the ties bear both a positive and negative character.

In particular, the indicators of creative thinking among students of humanities correlate with the coping strategy of "Confrontation", and among students of mathematics - with the coping mechanism aimed at planning the resolution of a stressful situation. This testifies to the fact that creatively developed students of the Faculty of Humanities react emotionally and confrontationally to problem situations, striving to solve them quickly; students of the Institute of Mathematics and Mechanics with a developed creative thinking systematically approach the solution of situations of stress, they analyze the possibilities and probable results of their actions.

The cognitive styles "Field dependence-Field independence" and the indicators of creative thinking do not depend on each other. The results obtained indicate an insignificant correlation of these variables among students of humanities and students-mathematicians. This may be associated with a number of reasons: the specificity of the sample, an insufficient number of respondents, which did not allow us to obtain statistically significant results.

The cognitive styles "Field dependence-Field independence" among students of the Faculty of Humanities are also correlated with coping mechanisms "Confrontation" and "Problem Solving Planning", and are also negatively related to the coping "Escape-Avoidance". This suggests that students of humanities have well-developed social skills, they are oriented to external factors, are emotionally unstable, which causes confrontation towards other participants of the problem, they are often dependent on the group, while solving difficult situations they listen to an authoritative opinion. Whereas students-mathematicians' cognitive styles correlated with coping mechanisms of "Self Control" and "Problem Solving Planning". This suggests that students of mathematics, when communicating with others, are cautious, independent, less prone to emotional outbursts, have self-control, they are critical, demanding, and are able to bear responsibility for their actions, which helps them to plan and predict the most effective ways out of existing stress situations (Akhtamyanova, 2017; Chernetskaya, 2009; Kalinina et al., 2016; Kalinina et al., 2017; Saidova, 2015; Vakarev, 2015; Vasyakin et al., 2015).

\section{CONCLUSION AND RECOMMENDATIONS}

The interpretation of research results allowed us to draw the main conclusions: students of humanities with developed creative thinking are focused on external factors, do not avoid solving a problem, but when they encounter a problem situation, the primary negative reaction prevents them from solving it quickly, thereby enabling them to correctly plan and find optimal ways out of this stressful situation; creative students- 
mathematicians are less susceptible to external factors, have high emotional control, are able to generate new solutions, which allows them to take conscious steps to solve the problem.

Thus, the results of our work partly have confirmed the ideas and research results of other authors that there is an interrelationship between the indicators of creative thinking, cognitive styles and methods of coping behavior.

\section{ACKNOWLEDGEMENT}

The work is performed according to the Russian Government Program of Competitive Growth of Kazan Federal University.

\section{REFERENCES}

Akhtamyanova, I. I. (2017). The interrelation of cognitive styles and types of thinking of pupils. Messenger of the Bashkir state pedagogical university of M. Akmulla, 3, 36-43.

Antsyferova, L. I. (1994). Personality in difficult life conditions: reconsideration, transformation of situations and psychological protection. Psychological magazine, 1, 3-18.

Belinskaya, D. B., \& Pronina, E. V. (2017). Modeling of psychological selection and training of personnel and its impact on economic efficiency. Economics and Entrepreneurship, 4(2), 1010-1014.

Bogoyavlenskaya, D. B. (2011). Opening section. Education personality, 3, 77-84.

Bogoyavlenskaya, D.B. (2002). Psychology of creativity. Moscow: Progress.

Bruner, J. (1971). About cognitive development. Study of the development of cognitive activity. Moscow: Pedagogy.

Bruner, J. (1977). Psychology of knowledge. Outside immediate information. Moscow: Progress.

Carrol, J. B. (1993). Human cognitive abilities: a survey of factor-analytic studies. Cambridge: Cambridge University Press. https:/ / doi.org/10.1017/CBO9780511571312

Chernetskaya, N. I. (2009). Creative thinking as the highest form of thinking. Messenger of the Adygei state university. Series 3: Pedagogy and psychology, 2, 225-230.

Gnedova, S. B., Emelyanenkova, A. V., Mikhailova, I. V., Sedunova, A. S., Enyashina, N. G., \& Salakhova, V. B. (2015). Individual Characteristics of Students in the Course of Professional Development (as Exemplified by the Ulyanovsk Region of Russia). Asian Social Science, 11(3), 168-176.

Guilford, J. (2015). Three parties of intelligence. Psychology of thinking. Moscow: Progress.

Kalinina, N. V., Kalinin, I. V., Salakhova, V. B., Oschepkov, A. A., \& Simanovskaja, M. A. (2016). The Use of Social Resources of Inclusive Educational Environment to Cope Difficult Situations by Adolescents. IEJMEMathematics Education, 11(7), 2527-2536.

Kalinina, N. V., Salakhova, V. B., Artamonova, E. G., Efimova, O. I., \& Kalinin, I. V. (2017). Psychological Prevention Mechanisms of Minors' Deviant Behavior. Eurasian Journal of Analytical Chemistry, 12, 663-672. https:/ / doi.org/10.12973/ ejac.2017.00200a

Kholodnaya, M. A. (2004). Cognitive styles: About the nature of individual mind. St. Petersburg: Peter.

Kryukova, T. L. (2008). Coping behavior: current state and prospects. Moscow: Publishing house «Institute of Psychology of RAS».

Lazarus, R. S., \& Folkman, S. (1984). Stress, appraisal and coping. New York: Springer Publishing.

Lipatova, N. V., Salakhova, V. B., Chertushkina, T. A., Ermolayeva, S. V., Mikhaylova, I. V., Shrol, O. Y., \& Panteleev, S. V. (2015). An adaptive man: hardiness resources in the conditions of system crises at the turn of the xix-xx and the XX-XXI centuries. Mediterranean Journal of Social Sciences, 6(2), 136-141. https:// doi.org/10.5901/mjss.2015.v6n2s3p136

Masalimova, A. R., \& Chibakov, A. S. (2016). Experimental analytical model of conditions and quality control of vocational training of workers and specialists. Mathematics Education, 11(6), 1796-1808.

Masalimova, A. R., \& Shaidullina, A. R. (2017). Diversification of Professional On-the-Job Training Models and Forms in Contemporary Business Conditions. Modern Journal of Language Teaching Methods, 7(3), 554-561.

Masalimova, A. R., Schepkina, N. K., Leifa, A. V., Shaidullina, A. R., \& Burdukovskaya, E. A. (2014). Mentoring perfection in modern enterprises conditions: practical recommendations. American Journal of Applied Sciences, 11(7), 1152-1156. https:/ / doi.org/10.3844/ajassp.2014.1152.1156

Saidova, Z. H. (2015). The main directions of research of creative thinking in domestic and foreign psychology. The young scientist, 23, 901-905.

Torrens, E. P. (2006). The Manifesto: A Guide to Developing a Creative Career. New York: Ablex Publishing. 
Vakarev, E. S. (2015). The interrelation of cognitive styles and creativity of the personality. Bulletin of Tomsk State Pedagogical University, 49(1), 347-355.

Vasyakin, B. S., Berezhnaya, M. S., Pozharskaya, E. L., \& Deberdeeva, N. A. (2015). 'Adaptation of graduates and students of regions to education in higher education institutions of Russia by means of social-psychological training'. Review of European Studies, 7(3), 88-89. https:/ / doi.org/10.5539/res.v7n3p88

Witkin, G, \& Goodenough, D. R. (1981). Cognitive Styles: Essence and Origins: Field Dependence and Field Independence. New York: International Universities Press.

\section{http://www.ejmste.com}

